\title{
\begin{tabular}{l|l} 
Mibraries & DSpace@MIT
\end{tabular}
}

\author{
MIT Open Access Articles
}

Red Phosphorescence from

Benzo[2,1,3]thiadiazoles at Room Temperature

The MIT Faculty has made this article openly available. Please share how this access benefits you. Your story matters.

Citation: Gutierrez, Gregory D., Graham T. Sazama, Tony Wu, Marc A. Baldo, and Timothy M. Swager. "Red Phosphorescence from Benzo[2,1,3]thiadiazoles at Room Temperature." The Journal of Organic Chemistry 81, no. 11 (June 3, 2016): 4789-4796. doi:10.1021/acs.joc.6b00789.

As Published: http://dx.doi.org/10.1021/acs.joc.6b00789

Publisher: American Chemical Society (ACS)

Persistent URL: http://hdl.handle.net/1721.1/109933

Version: Author's final manuscript: final author's manuscript post peer review, without publisher's formatting or copy editing

Terms of Use: Article is made available in accordance with the publisher's policy and may be subject to US copyright law. Please refer to the publisher's site for terms of use. 


\title{
HHS Public Access
}

Author manuscript

J Org Chem. Author manuscript; available in PMC 2016 June 03.

Published in final edited form as:

J Org Chem. 2016 June 3; 81(11): 4789-4796. doi:10.1021/acs.joc.6b00789.

\section{Red Phosphorescence from Benzo[2,1,3]thiadiazoles at Room Temperature}

\author{
Gregory D. Gutierrez ${ }^{\dagger}$, Graham T. Sazama ${ }^{\dagger}$, Tony $\mathbf{W u}^{\ddagger}$, Marc A. Baldo ${ }^{\ddagger}$, and Timothy M. \\ Swager ${ }^{*}, \dagger$ \\ †Department of Chemistry, Massachusetts Institute of Technology, Cambridge, MA 02139, United \\ States \\ FDepartment of Electrical Engineering and Computer Science, Massachusetts Institute of \\ Technology, Cambridge, MA 02139, United States
}

\section{Abstract \\ We describe the red phosphorescence exhibited by a class of structurally simple benzo[2,1,3]thiadiazoles at room temperature. The photophysical properties of these molecules in deoxygenated cyclohexane, including their absorption spectra, steady-state photoluminescence and excitation spectra, and phosphorescence lifetimes, are presented. Time-dependent density functional theory (TD-DFT) calculations were carried out to better understand the electronic excited states of these benzo[2,1,3]thiadiazoles and why they are capable of phosphorescence.}

\section{Graphical Abstract}
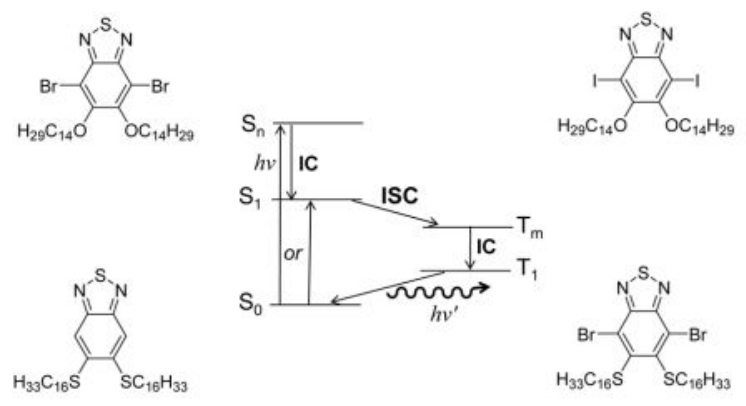

\section{INTRODUCTION}

Molecules capable of phosphorescence at room temperature have been utilized in a variety of technologies, most notably in light-emitting diodes (LEDs) for next-generation electronic displays. ${ }^{1}{ }^{2}$ Organometallic complexes containing platinum or iridium are often bright phosphorescent emitters because spin-orbit coupling induced by these heavy metal atoms

\footnotetext{
*Corresponding Author: ; Email: tswager@mit.edu

Notes

The authors declare no competing financial interests.

Supporting Information. ${ }^{1} \mathrm{H}$ and ${ }^{13} \mathrm{C}$ NMR spectra and TD-DFT data.
} 
bypass the quantum mechanical restrictions that prevent intersystem crossing (ISC) from occurring. ${ }^{3}$ Non-metallated organic molecules are also capable of ISC and are commonly investigated as triplet photosensitizers. ${ }^{4}$ However, other classes of such materials may also produce phosphorescence at room temperature. For example, phosphorescent emission under ambient conditions has been observed from organic molecules dispersed in polymeric hosts ${ }^{5}{ }^{9}$, zeolites, ${ }^{10}$ and various classes of non-metallated solids, including halogenated benzophenones ${ }^{11}$ and benzaldehydes, ${ }^{12},{ }^{13}$ carbazole-containing materials, ${ }^{14}, 15$ naphthalene diimides, ${ }^{16}$ persulfurated aromatics, ${ }^{17}{ }^{19}$ and tellurophenes. ${ }^{20},{ }^{21}$ However, observing measurable phosphorescence from metal-free organic molecules dissolved in liquids at room temperature is often a challenging feat due to rapid non-radiative dissipation of a triplet state's energy under these conditions. As a result, few non-metallated organic molecules are known to produce significant phosphorescence in solution at room temperature. ${ }^{22} 25$

Benzo[2,1,3]thiadiazoles constitute a category of heteroaromatic molecules that are widely used in the development of fluorescent $\pi$-conjugated organic materials. ${ }^{26}$ We herein present the room-temperature red phosphorescence exhibited by four benzo[2,1,3]thiadiazoles in cyclohexane and describe their corresponding excited-state electronic properties using computational methods.

\section{RESULTS AND DISCUSSION}

Our study was prompted by the observation of room-temperature phosphorescence from 4,7dibromo-5,6-bis(tetradecyloxy)benzo[2,1,3]thiadiazole (1-Br, Figure 1a) and 4,7-diiodo-5,6bis(tetradecyloxy)benzo[2,1,3]thiadiazole (1-I, Figure 1d), both of which are heteroaromatic linkers our laboratory has used to construct fluorescent semiconducting polymers. ${ }^{27},{ }^{28}$ The absorption spectra of these two molecules in cyclohexane at $50 \mu \mathrm{M}$ are primarily confined to the ultraviolet region and under aerobic conditions these solutions exhibit extremely weak blue fluorescence when excited at $\lambda_{\mathrm{ex}}=370 \mathrm{~nm}$. However, after deoxygenation with $\mathrm{N}_{2}$ gas, 1-Br and 1-I demonstrate profoundly red-shifted emission maxima at $\lambda_{\max }=642 \mathrm{~nm}$ and $\lambda_{\max }=643 \mathrm{~nm}$, respectively (Figures $1 \mathrm{~b}$ and 1e). We assigned these unexpected red emissions as phosphorescence ${ }^{29}$ as a result of the large downconversions of absorbed energy that results from ISC as well as the oxygen quenching of the long-lived triplet states. The phosphorescence quantum yields $\left(\Phi_{P}\right)$ of $\mathbf{1 - B r}$ and $\mathbf{1 - I}$ in degassed cyclohexane are $0.55 \%$ and $0.59 \%$, respectively. Excitation spectra monitored at $\lambda_{\mathrm{em}}=575 \mathrm{~nm}$ confirm that phosphorescence originates from 1-Br and 1-I by matching the structure of their corresponding absorption spectra (Figures 1c and 1f).

Because phosphorescence requires molecules to undergo ISC, the resulting photoluminescence lifetimes $\left(\tau_{P}\right)$ often occur on microsecond or millisecond time scales. Time-dependent transient photoluminescence spectroscopy was employed to determine if deoxygenated solutions of 1-Br and 1-I in cyclohexane possess such long lifetimes. Under these conditions, the photoluminescence of each sample undergo monoexponential decays on the microsecond-time scale (Figure 2). By fitting the intensities of the delayed responses to a first-order kinetic model with respect to time, the data reveal that 1-Br and 1-I possess $\tau_{P}$ of $2.8 \mu$ s and $3.6 \mu$ s, respectively. 
Following these results, we hypothesized that 1-Br and 1-I may be undergoing ISC and phosphorescence as a result of the influence of the heavy halides on their electronic properties. To investigate this possibility, we synthesized dichloride $\mathbf{1 - C l}$ and examined its photophysical properties in cyclohexane. 1-Cl was accessed by reacting 5,6bis(tetradecyloxy)benzo[2,1,3]thiadiazole with $N$-chlorosuccinimide in the presence of iron(III) chloride (Scheme 1). Although it possesses an absorption spectrum similar to those of 1-Br and 1-I, 1-Cl primarily demonstrates blue fluorescence at $\lambda_{\max }=424 \mathrm{~nm}$ with almost no red emission under deoxygenated conditions (Figure 3). Our results support the possibility that phosphorescence is facilitated by a heavy atom effect induced by the bromides and iodides in 1-Br and 1-I, respectively (see Calculations).

We next investigated if previously unreported benzo[2,1,3]thiadiazoles are also phosphorescent. In particular, we prepared the molecules 5,6bis(hexadecylthio)benzo[2,1,3]thiadiazole $(\mathbf{2}-\mathbf{H})^{30}$ and 4,7-dibromo-5,6bis(hexadecylthio)benzo[2,1,3]thiadiazole (2-Br), the syntheses of which are presented in Scheme 2. To construct 2-H, two equivalents of 1-hexadecanethiol were directly coupled with 5,6-dibromobenzo[2,1,3]thiadiazole using the palladium-catalyzed methodology developed by Itoh and Mase. ${ }^{31} \mathbf{2 - B r}$ was subsequently synthesized via iodine-catalyzed bromination of $\mathbf{2}-\mathbf{H}$.

The absorption and photoluminescence spectra of $50 \mu \mathrm{M}$ solutions of $\mathbf{2}-\mathbf{H}$ and $\mathbf{2}-\mathbf{B r}$ in cyclohexane are displayed in Figures $4 \mathrm{~b}$ and $4 \mathrm{e}$. The solutions of $\mathbf{2}-\mathbf{H}$ and $\mathbf{2}-\mathbf{B r}$ absorb only in the UV and blue regions, but produce red emissions after deoxygenation with $\mathrm{N}_{2}$ gas. 2-H and $2-\mathbf{B r}$ thus demonstrate phosphorescence with maxima at $\lambda_{\max }=624 \mathrm{~nm}$ and $\lambda_{\max }=667$ $\mathrm{nm}$, respectively, with corresponding excitation spectra resembling their absorption profiles (Figure 4c and 4f). In the case of $\mathbf{2 - H}$, the excitation spectrum fully matches its absorption spectrum at much lower concentrations (i.e. $2.6 \mu \mathrm{M}$ ), an observation which is most likely the result of an inner-filter effect occurring at $50 \mu \mathrm{M}$. Both molecules also possess values of $\Phi_{P}$ similar to those of $\mathbf{1 - B r}$ and $\mathbf{1 - I}(0.70 \%$ for $\mathbf{2}-\mathbf{H}$ and $0.50 \%$ for $\mathbf{2}-\mathbf{B r})$ in cyclohexane. Transient photoluminescence data indicate that $\tau_{P}$ is $5.4 \mu$ s for $\mathbf{2}-\mathbf{H}$ and $3.4 \mu$ s for $\mathbf{2}-\mathbf{B r}$ (Figures $4 \mathrm{~g}$ and $4 \mathrm{~h}$ ). A summary of the photophysical properties of the four phosphorescent molecules described thus far is presented in Table 1.

\section{CALCULATIONS}

We next performed a computational analysis of the electronic excited states of the studied benzo[2,1,3]thiadiazoles in order to determine potential phosphorescence pathways. After ground state geometry optimization of model structures $\mathbf{1 - C l}$, $\mathbf{1 - B r}$, and $\mathbf{1 - I ^ { * }}$, for which the large tetradecyloxy groups are replaced with propoxy substituents for computational efficiency, we carried out time-dependent density functional theory (TD-DFT) calculations to determine a mechanism for ISC. Throughout our analysis, we assume that internal conversion to $S_{1}$ always occurs prior to ISC (Kasha's rule). ${ }^{33}$ For each molecule, two triplet states $\left(\mathrm{T}_{1}\right.$ and $\left.\mathrm{T}_{2}\right)$ lie below the energy level of $\mathrm{S}_{1}$ and thus provide thermodynamically favorable routes for ISC (Figure 5a). We subsequently characterized the excited states of the molecules using Kohn-Sham orbitals to depict the electronic configurational descriptions of the $S_{1}, T_{1}$, and $T_{2}$ states of each molecule (Figure $5 \mathrm{~b}$ ). We observe that, in all three 
molecules, the $\mathrm{S}_{1}, \mathrm{~T}_{1}$, and $\mathrm{T}_{2}$ states can all be described as symmetric $\pi \rightarrow \pi^{*}$ configurations. $S_{1}$ and $\mathrm{T}_{1}$ are $288 \%$ described by a HOMO $\rightarrow$ LUMO configuration, while $\mathrm{T}_{2}$ corresponds to a HOMO- $1 \rightarrow$ LUMO configuration ( $>85 \%$ character). Because the transition symmetry of $S_{1}$ does not change during conversion to one of the lower-energy triplet states, ISC is most likely to be an inefficient process unless perturbations from one or more heavy atoms are introduced. ${ }^{34}$ We conclude that ISC from $S_{1}$ to $T_{2}$ or $T_{1}$ could be facilitated by the heavy bromides and iodides through second-order perturbations such as a spin-orbit-vibronic interaction. ${ }^{35}$ The lighter chlorides of $\mathbf{1 - C l}$ * likely do not carry a large enough atomic number to enable ISC in this manner, which explains why fluorescence dominates the photoluminescence spectrum of 1-Cl.

Figure 6 displays the excited-state energy level diagrams for $\mathbf{2}-\mathbf{H}^{*}$ and $\mathbf{2}-\mathbf{B r}$, model systems where the long alkyl chains of the thioethers have been replaced with propylthio groups (Figure 6a). ${ }^{36}$ The corresponding Kohn-Sham orbitals for $\mathrm{S}_{1}, \mathrm{~T}_{1}$, and $\mathrm{T}_{2}$ are shown in Figure 6b. Unlike the other phosphors, 2-H does not possess heavy halides that can enable ISC. However, the $\mathrm{S}_{1}$ transition of $\mathbf{2}-\mathbf{H}^{*}$ is an $\left(n, \pi^{*}\right)$ state in which most of the orbital density is concentrated at the sulfur atoms of the alkylthio groups. $\mathrm{T}_{1}$ is best represented as a $\left(\pi, \pi^{*}\right)$ state composed of a linear combination of configurations of HOMO-1 $\rightarrow$ LUMO (49\% character, $\left.\left(\pi, \pi^{*}\right)\right)$ and HOMO-2 $\rightarrow$ LUMO (44\% character, $\left.\left(n, \pi^{*}\right)\right)$. $\mathrm{T}_{2}$, on the other hand, is a mix of mostly an $\left(n, \pi^{*}\right)$ state with minority $\left(\pi, \pi^{*}\right)$ character represented by two configurations: HOMO $\rightarrow$ LUMO $\left(81 \%\right.$ character, $\left.\left(n, \pi^{*}\right)\right)$ and HOMO-3 $\rightarrow$ LUMO $(15 \%$ character, $\left.\left(\pi, \pi^{*}\right)\right)$. In this case, ISC is most likely possible by coupling a change in the spin angular momentum of the excited-state electron with the difference in the transition symmetries of the $S_{1}$ and $T_{1}$ manifolds (El-Sayed's rule). ${ }^{37}$ Similarly, $S_{1}$ of $\mathbf{2}-\mathbf{B r} \mathbf{r}^{*}$ is an $\left(n, \pi^{*}\right)$ state ${ }^{38}$ whereas $\mathrm{T}_{1}$ is a $\left(\pi, \pi^{*}\right)$ state and $\mathrm{T}_{2}$ is mostly $\left(n, \pi^{*}\right)$. Thus, we conclude that a difference in angular orbital momentum between excited states can also lead to ISC.

\section{CONCLUSION}

To conclude, we have presented a set of structurally simple benzo[2,1,3]thiadiazoles with unusual phosphorescent emissions at room temperature. The rare solution-phase photophysical properties of these species provide a new direction aimed at uncovering new classes of metal-free organic phosphorescent materials. We are currently seeking to discover new molecular motifs and realize their potential as the active components of inexpensive LEDs and other optoelectronic technologies.

\section{EXPERIMENTAL SECTION}

\section{Materials and Instrumentation}

Unless otherwise stated, all solvents and reagents were used as purchased. Anhydrous toluene was obtained from a solvent purification system and stored over activated $3 \AA$ molecular sieves. HPLC-grade cyclohexane was the solvent in all photophysical studies. 5,6dibromobenzo[2,1,3]thiadiazole was purchased from TCI Chemical Company and used without further purification. 1-I was synthesized according to a literature procedure. ${ }^{28}$ Column chromatography was carried out using silica gel (Aldrich, 60 A pore size, 230-400 mesh) and thin layer chromatography (TLC) was performed with silica gel TLC plates (J. T. 
Baker). NMR spectra $\left({ }^{1} \mathrm{H}: 400 \mathrm{MHz},{ }^{13} \mathrm{C}: 101 \mathrm{MHz}\right)$ were obtained with $\mathrm{CDCl}_{3}$ as the solvent and were referenced relative to resonances corresponding to $\mathrm{CDCl}_{3}\left({ }^{1} \mathrm{H}: \delta=7.26\right.$ ppm; $\left.{ }^{13} \mathrm{C}: \delta=77.16 \mathrm{ppm}\right)$. NMR spectra were referenced relative to resonances corresponding to the solvent $\left({ }^{1} \mathrm{H}: \delta=7.26 \mathrm{ppm} ;{ }^{13} \mathrm{C}: \delta=77.16 \mathrm{ppm}\right)$. Peak multiplicities are designated as singlet ("s"), triplet ("t"), or multiplet ("m"). High-resolution mass spectrometry (HRMS) measurements were carried out in direct analysis in real time (DART) or with electrospray ionization (ESI) in positive mode using a Fourier transform-ion cyclotron resonance mass spectrometer.

All absorption spectra were measured with a UV/vis spectrophotometer under aerobic conditions. Photoluminescence spectra and excitation spectra were obtained with a spectrofluorometer employing a $450 \mathrm{~W}$ xenon short-arc lamp. Excitation and emission bandpass slits were set at $3 \mathrm{~nm}$ and $5 \mathrm{~nm}$, respectively, and data were acquired with the excitation beam and detector oriented at a right angle. Photoluminescence spectra were corrected to account for wavelength-dependent responses by the detector, while excitation spectra were referenced relative to variations in the lamp intensity with wavelength. Phosphorescence quantum yields were measured using the relative method suggested by Brouwer $^{39}$ with all absorbances at the excitation wavelength maintained below 0.05 to prevent inner-filter effects from occurring. For these photoluminescence measurements, screw-top quartz cuvettes covered with a septum cap were used to hold solutions and were deoxygenated by purging them with $\mathrm{N}_{2}$ gas for about 10 minutes to induce phosphorescence. For best results, solutions analyzed by spectroscopy were not exposed to UV radiation during the deoxygenation process.

To obtain transient photoluminescence lifetime measurements, a sample was placed in a quartz tube (6-mm outer diameter, 4-mm inner diameter) and sealed with a small septum. The solution was then deoxygenated via purging with $\mathrm{N}_{2}$ gas for about 5 minutes. A $170 \mu \mathrm{J}$ pulsed $337 \mathrm{~nm} \mathrm{~N} \mathrm{~N}_{2}$ laser was used as the excitation source with photoluminescence detected using a silicon detector coupled to a $400 \mathrm{~nm}$ longpass optical filter. The resulting timedependent photoluminescence data were recorded with an oscilloscope. Some residual laser signal is present as the prompt component of these decays and were not considered in our analysis. To extract the lifetime, data past this artificial prompt signal (i.e. after $1 \mu \mathrm{s}$ ) was subjected to a linear fit on the logarithmic scale.

\section{Electronic Structure Calculations}

Molecules were built and molecular mechanics were used to minimize geometries using Avogadro. ${ }^{40}$ TD-DFT calculations were performed using the ORCA software package. ${ }^{41}{ }^{43}$ First, geometries were optimized using the AccOpt standard calculation level implemented in ORCA (BP86 functional, ${ }^{44}$ ORCA default basis 4: TZVP(2d) for all non-hydrogens, and $\operatorname{TZV}(\mathrm{p})$ for hydrogens ${ }^{45}$ ). Numerical frequencies were then calculated to determine that geometries represented minima on the potential energy surface. Using the optimized geometries, TD-DFT calculations ${ }^{42}$ were carried out using the same bases, with the PBE0 functional ${ }^{46}$ and increased grid accuracy, and the resolution of identity chain-of-spheres module, RIJCOSX, ${ }^{43}$ was used to reduce the computational cost of the calculations. The first 10 excited state levels and their excitation profiles were calculated for each molecule at 
the ground state geometry, for both singlet and triplet states, affording a first-order description of the energetic landscape. Electronic configuration descriptions of the relevant excited states $\left(S_{1}, T_{1}\right.$, and $\left.T_{2}\right)$ were visualized using Kohn-Sham orbitals depicted using the Avogadro software with extended ORCA support. All simulated molecules were treated without solvation (i.e. gas phase).

4,7-Dichloro-5,6-bis(tetradecyloxy)benzo[2,1,3]thiadiazole (1-Cl)—To an ovendried 2-neck $100 \mathrm{~mL}$ round-bottom flask equipped with a magnetic stir bar and condenser were combined 5,6-bis(tetradecyloxy)benzo[2,1,3] thiadiazole ${ }^{27}(300 \mathrm{mg}, 0.535 \mathrm{mmol}), \mathrm{N}$ chlorosuccinimide $(157 \mathrm{mg}, 1.18 \mathrm{mmol})$, and anhydrous $\mathrm{CHCl}_{3}(30 \mathrm{~mL}) . \mathrm{FeCl}_{3}(101 \mathrm{mg}$, $0.628 \mathrm{mmol}$ ) was added to the stirring solution under a stream of argon. The reaction was stirred under argon at $50{ }^{\circ} \mathrm{C}$ for $72 \mathrm{~h}$. The reaction mixture was cooled to room temperature, diluted with $30 \mathrm{~mL} \mathrm{CHCl}_{3}$, and poured into $50 \mathrm{~mL} \mathrm{H}_{2} \mathrm{O}$. The organic layer was washed with $100 \mathrm{~mL} \mathrm{NaHCO}_{3}$ (aq.) and $100 \mathrm{~mL}$ saturated $\mathrm{NaCl}\left(\right.$ aq.), dried with $\mathrm{MgSO}_{4}$, filtered, and evaporated. The brown crude product was subjected to column chromatography $(1: 1$ $\mathrm{CHCl}_{3}$ :hexanes) to furnish $\mathbf{1 - C l}$ as a white solid (117 mg, 35\% yield). $R_{f}=0.38\left(\mathrm{SiO}_{2} \mathrm{TLC}\right.$, 1:1 $\mathrm{CHCl}_{3}$ :hexanes). ${ }^{1} \mathrm{H} \mathrm{NMR}\left(400 \mathrm{MHz} \mathrm{CDCl}_{3}\right): \delta 4.18(\mathrm{t}, J=6.7 \mathrm{~Hz}, 4 \mathrm{H}), 1.87(\mathrm{~m}, 4 \mathrm{H})$, $1.53(\mathrm{~m}, 4 \mathrm{H}), 1.40-1.26(\mathrm{~m}, 40 \mathrm{H}), 0.88(\mathrm{t}, J=7.0 \mathrm{~Hz}, 6 \mathrm{H}) .{ }^{13} \mathrm{C} \mathrm{NMR}\left(101 \mathrm{MHz}, \mathrm{CDCl}_{3}\right): \delta$ 153.3, 149.8, 116.4, 75.4, 32.1, 30.4, 29.86, 29.85, 29.84, 29.82, 29.79, 29.76, 29.6, 29.5, 26.1, 22.9, 14.3. HRMS (ESI) $\mathrm{m} / z$ calculated for $\mathrm{C}_{34} \mathrm{H}_{58} \mathrm{Cl}_{2} \mathrm{~N}_{2} \mathrm{O}_{2} \mathrm{~S}[\mathrm{M}+\mathrm{H}]^{+}: 629.3669$, found: 629.3687 .

4,7-Dibromo-5,6-bis(tetradecyloxy)benzo[2,1,3]thiadiazole (1-Br)—Compound 1Br was synthesized as reported by Bouffard and Swager, ${ }^{27}$ but with modified purification. To a $50 \mathrm{~mL}$ round-bottom flask equipped with magnetic stirbar were combined 5,6bis(tetradecyloxy)benzo[2,1,3] thiadiazole (300 $\mathrm{mg}, 0.535 \mathrm{mmol}), \mathrm{CH}_{2} \mathrm{Cl}_{2}(15 \mathrm{~mL}$ ), and $\mathrm{AcOH}(7 \mathrm{~mL})$. To this solution was added $\mathrm{Br}_{2}(528 \mathrm{mg}, 0.169 \mathrm{mmol}, 0.17 \mathrm{~mL})$ dropwise. The flask was stoppered, wrapped with aluminum foil, and contents were stirred for 2 days. The reaction mixture was then poured into $50 \mathrm{~mL} 5 \% \mathrm{w} / \mathrm{v} \mathrm{Na}_{2} \mathrm{~S}_{2} \mathrm{O}_{3} \cdot 5 \mathrm{H}_{2} \mathrm{O}$ (aq.) and washed. The organic layer was then washed with 2 x $50 \mathrm{~mL}$ saturated $\mathrm{NaHCO}_{3}$ (aq.) and $50 \mathrm{~mL}$ saturated $\mathrm{NaCl}$ (aq.), dried with $\mathrm{MgSO}_{4}$, filtered, and evaporated. The crude residue was subjected to column chromatography $\left(3: 7 \mathrm{CHCl}_{3}\right.$ :hexanes) to yield $\mathbf{1 - B r}$ as a white solid (244 mg, 64\% yield). Characterization data is consistent with those already reported. ${ }^{1} \mathrm{H}$ NMR (400 MHz, $\left.\mathrm{CDCl}_{3}\right): \delta 4.16(\mathrm{t}, J=6.7 \mathrm{~Hz}, 4 \mathrm{H}), 1.88(\mathrm{~m}, 4 \mathrm{H}), 1.53(\mathrm{~m}, 4 \mathrm{H}), 1.38-1.26$ $(\mathrm{m}, 40 \mathrm{H}), 0.88(\mathrm{t}, J=7.0 \mathrm{~Hz}, 6 \mathrm{H})$.

5,6-Bis(hexadecylthio)benzo[2,1,3]thiadiazole (2-H)—To a $25 \mathrm{~mL}$ Schlenk flask equipped with a magnetic stirbar were added 5,6-dibromobenzo[2,1,3]thiadiazole (350 mg, $1.19 \mathrm{mmol}), \mathrm{Pd}_{2} \mathrm{dba}_{3}(27.3 \mathrm{mg}, 29.8 \mu \mathrm{mol})$, and XantPhos $(34.5 \mathrm{mg}, 59.3 \mu \mathrm{mol})$. The flask was then evacuated and backfilled with argon three times before adding anhydrous toluene (6 mL), diisopropylethylamine (2 mL), and 1-hexadecanethiol (954 mg, $1.14 \mathrm{~mL}, 3.69$ $\mathrm{mmol})$. After purging with argon for 15 minutes at room temperature, the reaction mixture was stirred at $80{ }^{\circ} \mathrm{C}$ under argon for $19 \mathrm{~h}$. The reaction mixture was then cooled to room temperature and filtered. Volatiles were then evaporated in vacuo. The crude residue was dissolved in $\mathrm{CH}_{2} \mathrm{Cl}_{2}$ and combined with $3 \mathrm{~g}$ silica gel. After removal of the solvent, the solid 
mixture was dry-loaded onto a silica gel column and the product was eluted out with 1:1 $\mathrm{CH}_{2} \mathrm{Cl}_{2}$ :hexanes. The recovered product was lastly recrystallized from isopropanol to obtain pure $2-\mathbf{H}$ as a light yellow solid ( $623 \mathrm{mg}, 81 \%$ yield). $R_{f}=0.49\left(\mathrm{SiO}_{2} \mathrm{TLC}, 1: 1\right.$ $\mathrm{CH}_{2} \mathrm{Cl}_{2}$ :hexanes) ${ }^{1} \mathrm{H}$ NMR (400 MHz, $\mathrm{CDCl}_{3}$ ): $\delta 7.68$ (s, 2H), 3.04 (t, $\left.J=7.4 \mathrm{~Hz}, 4 \mathrm{H}\right), 1.79$ (m, 4H), 1.50 (m, 4H), 1.35-1.25 (m, 48H), 0.87 (t, $J=7.0 \mathrm{~Hz}, 6 \mathrm{H}) .{ }^{13} \mathrm{C}$ NMR (101 MHz, $\left.\mathrm{CDCl}_{3}\right): \delta 153.4,142.3,116.0,33.6,32.1,29.84,29.81,29.78,29.7,29.6,29.5,29.33$, 29.25, 28.2, 22.8, 14.3. HRMS (DART) $\mathrm{m} / z$ calculated for $\mathrm{C}_{38} \mathrm{H}_{68} \mathrm{~N}_{2} \mathrm{~S}_{3}[\mathrm{M}+\mathrm{H}]^{+}$: 649.4617, found: 649.4617 .

4,7-Dibromo-5,6-bis(hexyldecylthio)benzo[2,1,3]thiadiazole (2-Br)—In a $50 \mathrm{~mL}$ round-bottom flask equipped with a magnetic stirbar, $\mathbf{2}-\mathbf{H}(100 \mathrm{mg}, 0.154 \mathrm{mmol})$ was dissolved in a mixture of $\mathrm{CH}_{2} \mathrm{Cl}_{2}(15 \mathrm{~mL})$ and $\mathrm{AcOH}(4 \mathrm{~mL})$ and chilled to $0{ }^{\circ} \mathrm{C}$. To the stirring suspension was added $\mathrm{I}_{2}(1.75 \mathrm{mg}, 7.70 \mu \mathrm{mol})$, followed by $\mathrm{Br}_{2}(123 \mathrm{mg}, 0.770$ $\mathrm{mmol}, 0.04 \mathrm{~mL}$ ) dropwise. Contents were warmed to room temperature and stirred in the dark for $48 \mathrm{~h}$. The reaction mixture was then poured into $50 \mathrm{~mL} 5 \% \mathrm{w} / \mathrm{v} \mathrm{Na} \mathrm{N}_{2} \mathrm{~S}_{3} \cdot 5 \mathrm{H}_{2} \mathrm{O}$ (aq.) and washed with $50 \mathrm{~mL}$ saturated $\mathrm{NaHCO}_{3}$ (aq.), and $50 \mathrm{~mL}$ saturated $\mathrm{NaCl}$ (aq.). The organic layer was dried with $\mathrm{MgSO}_{4}$ and filtered. Volatiles were evaporated and the crude residue was purified by column chromatography (3:7 $\mathrm{CHCl}_{3}$ :hexanes) to obtain $\mathbf{2}-\mathbf{B r}$ as a light yellow solid (79 mg, 64\% yield). $R_{f}=0.31\left(\mathrm{SiO}_{2} \mathrm{TLC}, 3: 7 \mathrm{CHCl}_{3}\right.$ :hexanes). ${ }^{1} \mathrm{H} \mathrm{NMR}$ (400 MHz, $\left.\mathrm{CDCl}_{3}\right): \delta 3.08(\mathrm{t}, J=7.4 \mathrm{~Hz}, 4 \mathrm{H}), 1.61(\mathrm{~m}, 4 \mathrm{H}), 1.42(\mathrm{~m}, 4 \mathrm{H}), 1.25-1.24(\mathrm{~m}$, $48 \mathrm{H}), 0.88(\mathrm{t}, J=7.0 \mathrm{~Hz}, 6 \mathrm{H}) .{ }^{13} \mathrm{C} \mathrm{NMR}\left(101 \mathrm{MHz}, \mathrm{CDCl}_{3}\right): \delta 153.0,144.5,122.6,38.4$, $32.1,29.84,29.82,29.81,29.79,29.73,29.65,29.5,29.3,29.0,22.8,14.3$. HRMS (DART) $\mathrm{m} / z$ calculated for $\mathrm{C}_{38} \mathrm{H}_{66} \mathrm{Br}_{2} \mathrm{~N}_{2} \mathrm{~S}_{3} \mathrm{M}^{+}$: 806.2741, found: 806.2734.

\section{Supplementary Material}

Refer to Web version on PubMed Central for supplementary material.

\section{Acknowledgments}

G.D.G. acknowledges the National Science Foundation Graduate Research Fellowship Program for support (Grant No. 1122374). G.T.S. was supported by a F32 Ruth L. Kirschtein NRSA Fellowship under award number GM112272. T.W. was supported by the U.S. Department of Energy, office of Basic Energy Sciences (Award No. DE-FG02-07ER46474). We thank Li Li for acquiring mass spectrometry data, Alex Kohn for insightful discussions, and Prof. Theodore Betley for computer time.

\section{References}

1. Müllen, K.; Scherf, U. Organic Light Emitting Devices: Synthesis, Properties, and Applications. Wiley-VCH; Hoboken, NJ: 2006.

2. Yersin, H. Highly Efficient OLEDs with Phosphorescent Materials. Wiley-VCH; Hoboken, NJ: 2008.

3. Evans RC, Douglas P, Winscom CJ. Coord Chem Rev. 2006; 250:2093-2126.

4. (a) Yogo T, Urano Y, Ishitsuka Y, Maniwa F, Nagano T. J Am Chem Soc. 2013; 127:12162-12163. [PubMed: 16131160] (b) Zhang C, Zhao J, Wu S, Wang Z, Wu W, Ma J, Guo S, Huang L. J Am Chem Soc. 2013; 135:10566-10578. [PubMed: 23790008] (c) Kamkaew A, Lim SH, Lee HB, Kiew LV, Chung LY, Burgess K. Chem Soc Rev. 2013; 42:77-88. [PubMed: 23014776] (c) Zhao J, Wu W, Sun J, Guo S. Chem Soc Rev. 2013; 42:5323-5351. [PubMed: 23450221]

5. (a) Horie K, Mita I. Chem Phys Lett. 1982; 93:61-65.(b) Horie K, Morishita K, Mita I. Macromolecules. 1984; 17:1746-1750. 
6. Lee D, Bolton O, Kim BC, Youk JH, Takayama S, Kim J. J Am Chem Soc. 2013; 135:6325-6329. [PubMed: 23521108]

7. Hirata S, Totani K, Zhang J, Yamashita T, Kaji H, Marder SR, Watanabe T, Adachi C. Adv Funct Mater. 2013; 23:3386-3397.

8. Kwon MS, Lee D, Seo S, Jung J, Kim J. Angew Chem Int Ed. 2014; 53:11177-11181.

9. Lee D, Jung J, Bilby D, Kwon MS, Yun J, Kim J. ACS Appl Mater Inter. 2015; 7:2993-2997.

10. Ramamurthy V, Caspar JV, Eaton DF, Kuo EW, Corbin DR. J Am Chem Soc. 1992; 114:38823892.

11. Yuan WZ, Shen XY, Zhao H, Lam JWY, Tang L, Lu P, Wang C, Liu Y, Wang Z, Zheng Q, Sun JZ, Ma Y, Tang BZ. J Phys Chem C. 2010; 114:6090-6099.

12. Bolton O, Lee K, Kim HJ, Lin KY, Kim J. Nat Chem. 2011; 3:205-210. [PubMed: 21336325]

13. Bolton O, Lee D, Jung J, Kim J. Chem Mater. 2014; 26:6644-6649.

14. Gao HY, Shen QJ, Zhao XR, Yan XQ, Pan X, Jin WJ. J Mater Chem. 2012; 22:5336-5343.

15. Yang Z, Mao Z, Zhang X, Ou D, Mu Y, Zhang Y, Zhao C, Liu S, Chi Z, Xu J, Wu YC, Lu PY, Lien A, Bryce MR. Angew Chem Int Ed. 2016; 55:2181-2185.

16. Ventura B, Bertocco A, Braga D, Catalano L, d'Agostino S, Grepioni F, Taddei P. J Phys Chem C. 2014; 118:18646-18658.

17. Bergamini G, Fermi A, Botta C, Giovanella U, Di Motta S, Negri F, Peresutti R, Gingras M, Ceroni P. J Mater Chem C. 2013; 1:2717-2724.

18. Fermi A, Bergamini G, Roy M, Gingras M, Ceroni P. J Am Chem Soc. 2014; 136:6395-6400. [PubMed: 24725096]

19. Fermi A, Bergamini G, Peresutti R, Marchi E, Roy M, Ceroni P, Gingras M. Dyes Pigments. 2014; 110:113-122.

20. He G, Torres Delgado W, Schatz DJ, Merten C, Mohammadpour A, Mayr L, Ferguson MJ, McDonald R, Brown A, Shankar K, Rivard E. Angew Chem Int Ed. 2014; 53:4675-4679.

21. He G, Wiltshire BD, Choi P, Savin A, Sun S, Mohammadpour A, Ferguson MJ, Farsinezhad S, Brown A, Shankar K, Rivard E. Chem Commun. 2015; 51:5444-5447.

22. Xu J, Takai A, Kobayashi Y, Takeuchi M. Chem Commun. 2013; 49:8447-8449.

23. Donkerbroek JJ, Elzas JJ, Gooijer C, Frei RW, Velthorst NH. Talanta. 1981; 28:717-723. [PubMed: 18962992]

24. Koch M, Perumal K, Blacque O, Garg JA, Saiganesh R, Kabilan S, Balasubramanian KK, Venkatesan K. Angew Chem Int Ed. 2014; 53:6378-6382.

25. (a) Scypinski S, Love LJC. Anal Chem. 1984; 56:322-327.(b) Hamai S. J Chem Soc, Chem Commun. 1994:2243-2244.(c) de la Pena AM, Salinas F, Gomez MJ, Sanchez-Pena M, DuranMenas I. Talanta. 1993; 40:1657-1664. [PubMed: 18965836]

26. Neto BAD, Lapis AAM, da Silva EN Júnior, Dupont J. Eur J Org Chem. 2013:228-255.

27. Bouffard J, Swager TM. Macromolecules. 2008; 45:5559-5562.

28. Gutierrez GD, Coropceanu I, Bawendi MG, Swager TM. Adv Mater. 2016; 28:497-501. [PubMed: 26596854]

29. While there have been many reports on the synthesis and use of $\mathbf{1 - B r}$ and its alkylated derivatives, no reports of red phosphorescence from this type of structure have previously been presented. Additionally, there are no previous reports of 1-I or known alkylated derivatives exhibiting phosphorescence. We note that the application of column chromatography to all molecules presented in this study removes impurities that obscure clear observations of phosphorescence.

30 . The synthesis of a benzo[2,1,3]thiadiazole functionalized with alkyl thioethers at the 4 and 7 positions has been reported. See: Liu X-Y, Usui T, Hanna J. Chem Eur J. 2012; 20:14207-14212. [PubMed: 25223273]

31. Itoh T, Mase T. Org Lett. 2004; 6:4587-4590. [PubMed: 15548082]

32. Heinrich G, Schoof S, Gusten H. J Photochem. 1974; 3:315-320.

33. Kasha M. Discuss Faraday Soc. 1950; 9:14-19.

34. Turro, NJ.; Ramamurthy, V.; Scaiano, JC. Modern Molecular Photochemistry of Organic Molecules. University Science Books; Sausalito, CA: 2010. 
35. El-Sayed MA. J Chem Phys. 1965; 43:2864-2872.

36. The alkyl chain was additionally changed to propyl to account for the very large electron density contributions from the sulfur atoms of the thioethers within the calculated occupied molecular orbitals.

37. (a) El-Sayed MA. J Chem Phys. 1962; 36:573-574.(b) El-Sayed MA. J Chem Phys. 1963; 38:2834-2838.

38. Because our calculations were carried out in the gas phase, the deviation of the calculated $\mathrm{S}_{1}$ state $(2.60 \mathrm{eV}, \lambda,=477 \mathrm{~nm})$ from experimental data $(\lambda, \sim 400-420 \mathrm{~nm})$ for 2-Br could largely be the result of a significant hypsochromic shift commonly exhibited by $n \rightarrow, \pi$, * transitions upon solvation. Although smaller, such a deviation is also observed for the $S_{1}$ state of $\mathbf{2}-\mathbf{H}$ (calculated wavelength for $\mathrm{S}_{1}$ : $402 \mathrm{~nm}$, observed: $382 \mathrm{~nm}$ ). See: Karelson M, Zerner MC. J Am Chem Soc. 1990; 112:9405-9406.

39. Brouwer AM. Pure Appl Chem. 2011; 83:2213-2228.

40. Hanwell MD, Curtis DE, Lonie DC, Vandermeersch T, Zurek E, Hutchison GR. J Cheminform. 2012; 4:1-17. [PubMed: 22236646]

41. Neese F. Wiley Interdiscip Rev Comput Mol Sci. 2012; 2:73-78.

42. Petrenko T, Krylova O, Neese F, Sokolowski M. New J Phys. 2009; 11:015001.

43. Neese F, Wennmohs F, Hansen A, Becker U. Chem Phys. 2009; 356:98-109.

44. (a) Becke AD. Phys Rev A. 1988; 38:3098-3100.(b) Perdew JP. Phys Rev B. 1986; 33:8822-8824.

45. (a) Schäfer A, Horn H, Ahlrichs R. J Chem Phys. 1992; 97:2571-2577.(b) Weigend F, Ahlrichs R. Phys Chem Chem Phys. 2005; 7:3297-3305. The Ahlrichs (2d,2p) polarization functions were obtained from the TurboMole basis set library under ftp.chemie.uni-karlsruhe.de/pub/basen. [PubMed: 16240044]

46. Adamo C, Barone V. J Chem Phys. 1999; 110:6158-6169. 

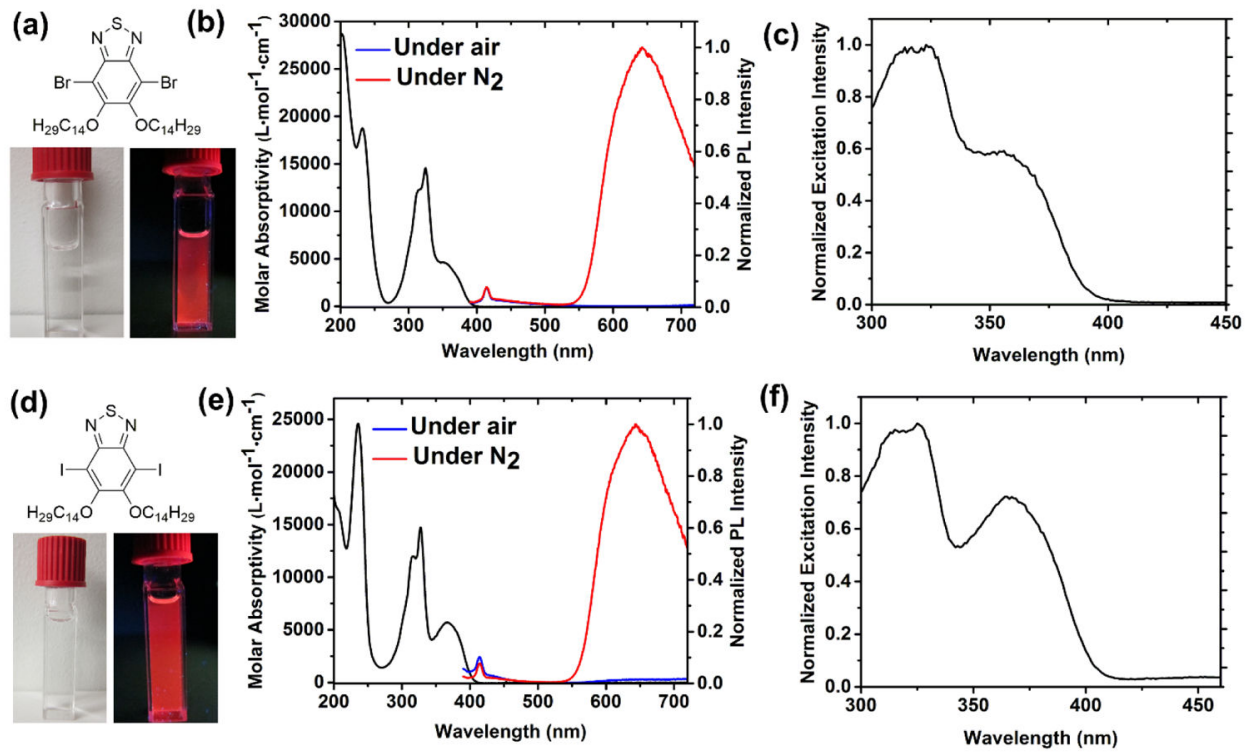

Figure 1.

Photophysical properties of phosphorescent compounds 1-Br and 1-I in cyclohexane. (a) 1$\mathbf{B r}$ and (d) 1-I and their appearance in degassed cyclohexane under normal and UV ( $\lambda=365$ $\mathrm{nm}$ ) lighting. (b) Absorption spectrum and photoluminescence spectra under air and $\mathrm{N}_{2}$ gas for 1-Br and (e) 1-I $\left(\lambda_{\mathrm{ex}}=370 \mathrm{~nm}\right)$. (c) Phosphorescence excitation spectrum of 1-Br and (f) 1-I $\left(\lambda_{\mathrm{em}}=575 \mathrm{~nm}\right)$. Photoluminescence and excitation spectra were measured for $50 \mu \mathrm{M}$ solutions. A small peak attributed to Raman scattering $\left(\lambda_{\max }=414 \mathrm{~nm}\right)$ of the excitation beam by the solvent overlaps with the fluorescence of all phosphorescent samples presented in this study and is not considered in our analysis. 
(a)

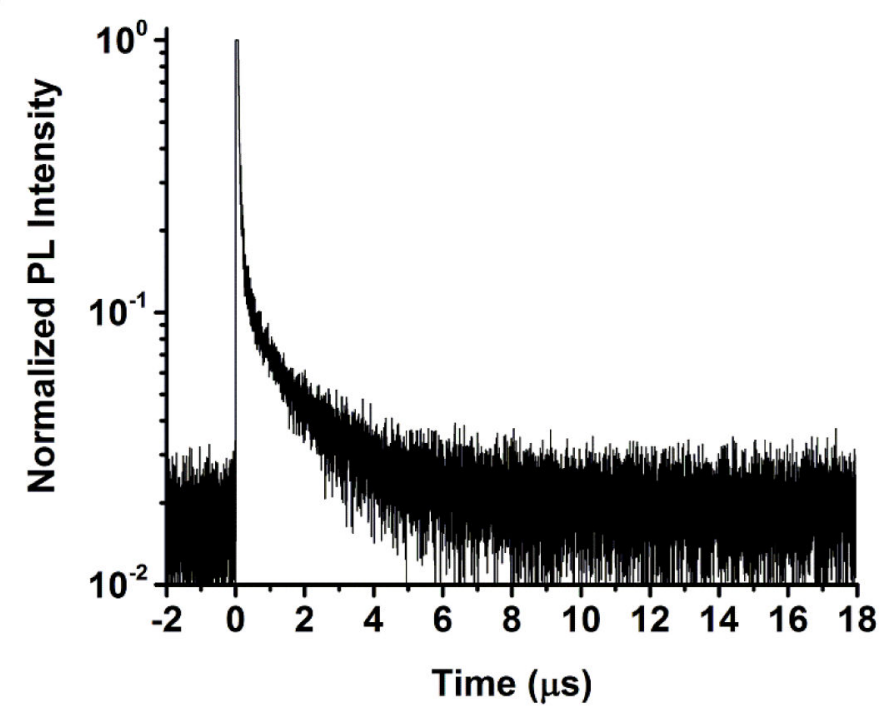

(b)

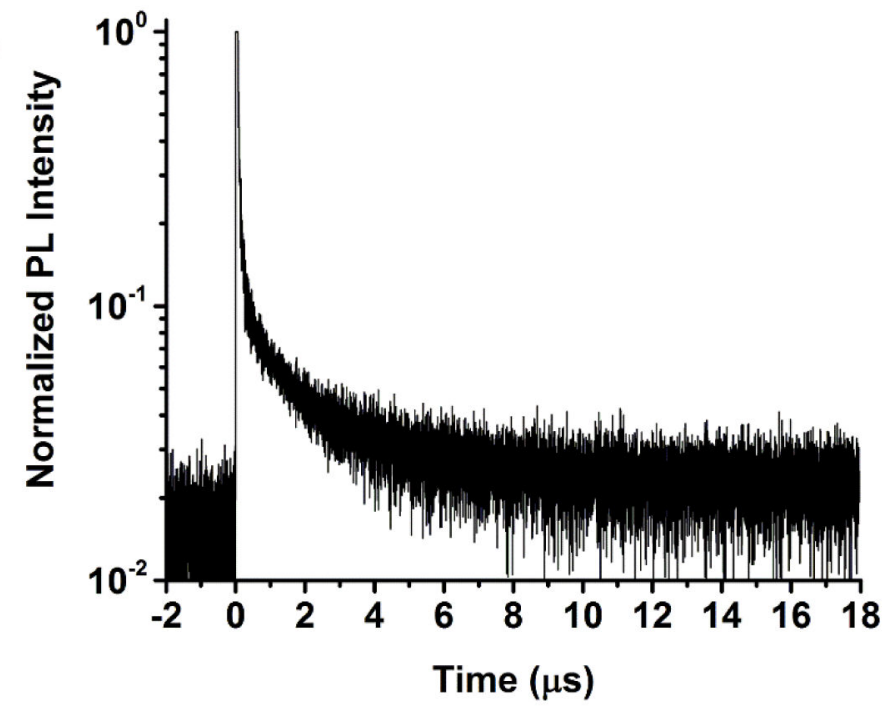

Figure 2.

Time-dependent photoluminescence decays of (a) $\mathbf{1}$-Br and (b) $\mathbf{1 - I}$ in cyclohexane (50 $\mu \mathrm{M})$ under inert atmosphere and at room temperature. 


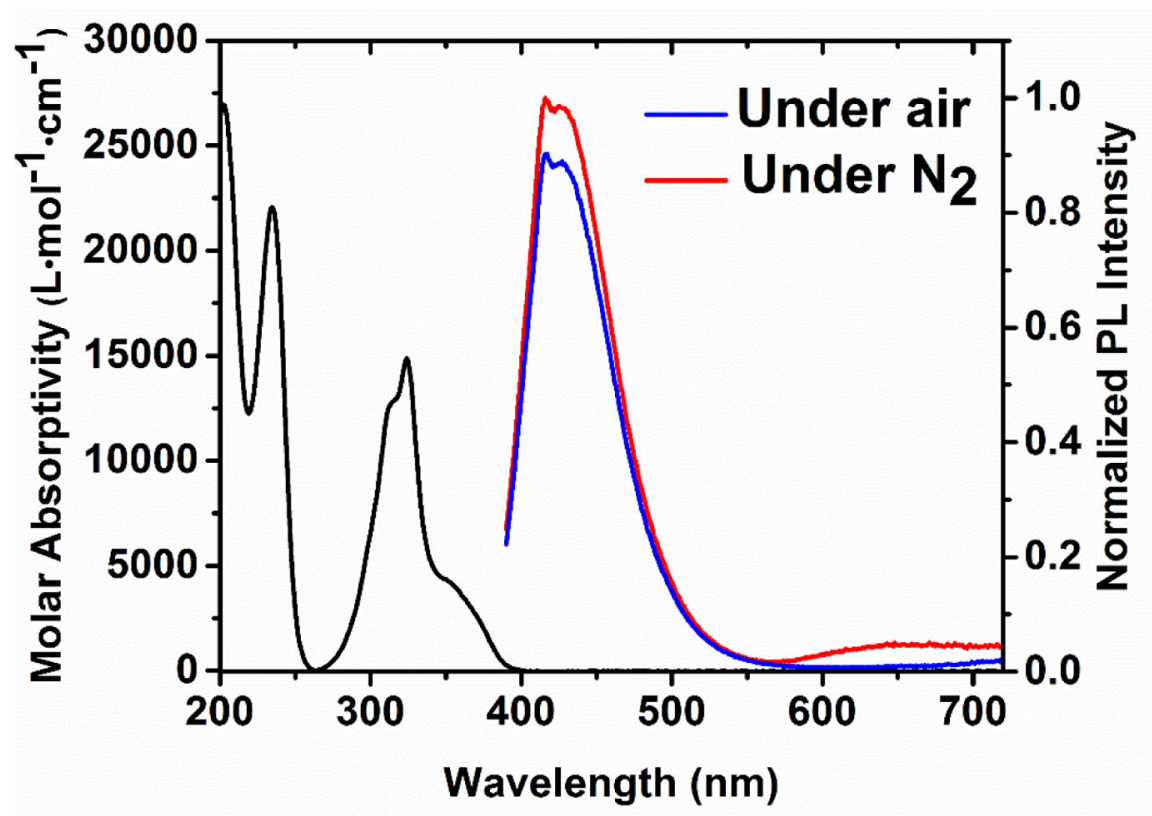

Figure 3.

Absorption and emission spectra of 1-Cl in cyclohexane. Emission spectra $\left(\lambda_{\mathrm{ex}}=370 \mathrm{~nm}\right)$ are reported for $50 \mu \mathrm{M}$ samples in aerobic and deoxygenated cyclohexane. 

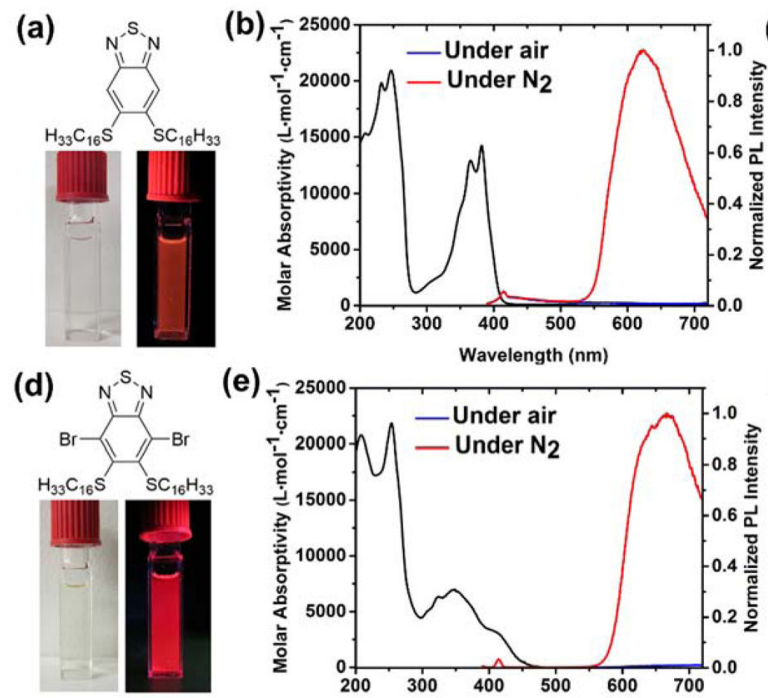

(e)

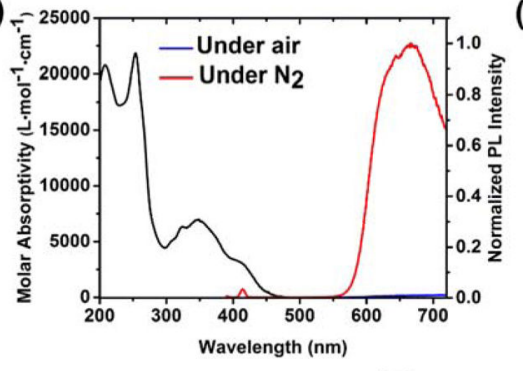

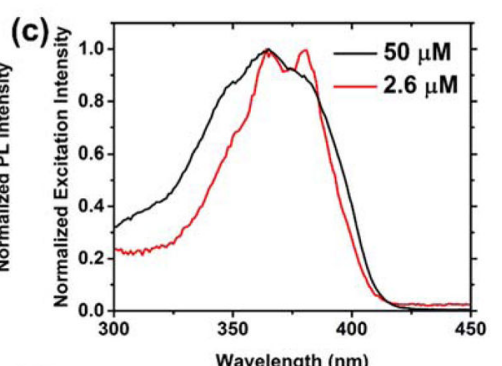

(f)

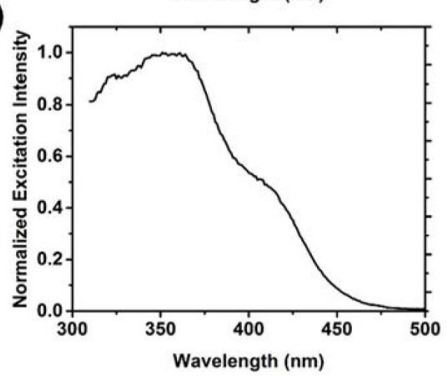

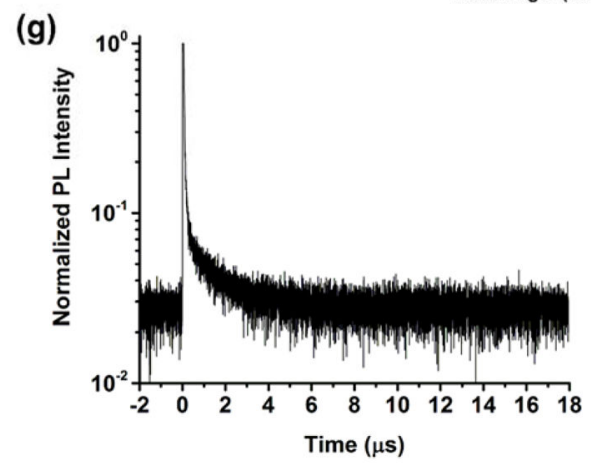

(h)

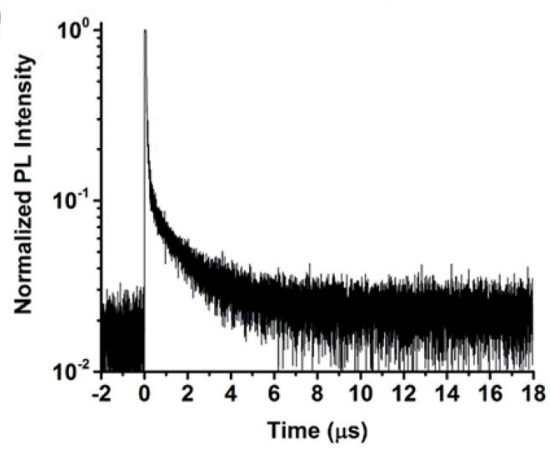

Figure 4.

(a) 2-H in cyclohexane with its (b) absorption spectrum and photoluminescence spectra under air and $\mathrm{N}_{2}$ gas and (c) phosphorescence excitation spectra at $50 \mu \mathrm{M}$ and $2.6 \mu \mathrm{M}\left(\lambda_{\mathrm{em}}=\right.$ $575 \mathrm{~nm}$ ). (d-f) 2-Br with its corresponding absorption/photoluminescence spectra $\left(\lambda_{\text {ex }}=\right.$ $370 \mathrm{~nm}, 50 \mu \mathrm{M})$ and phosphorescence excitation spectrum $\left(\lambda_{\mathrm{em}}=600 \mathrm{~nm}, 50 \mu \mathrm{M}\right) .(\mathrm{g})$ Time-dependent photoluminescence decays for $\mathbf{2}-\mathbf{H}$ and (h) $\mathbf{2}-\mathbf{B r}$ in deoxygenated cyclohexane at $50 \mu \mathrm{M}$. 
a.

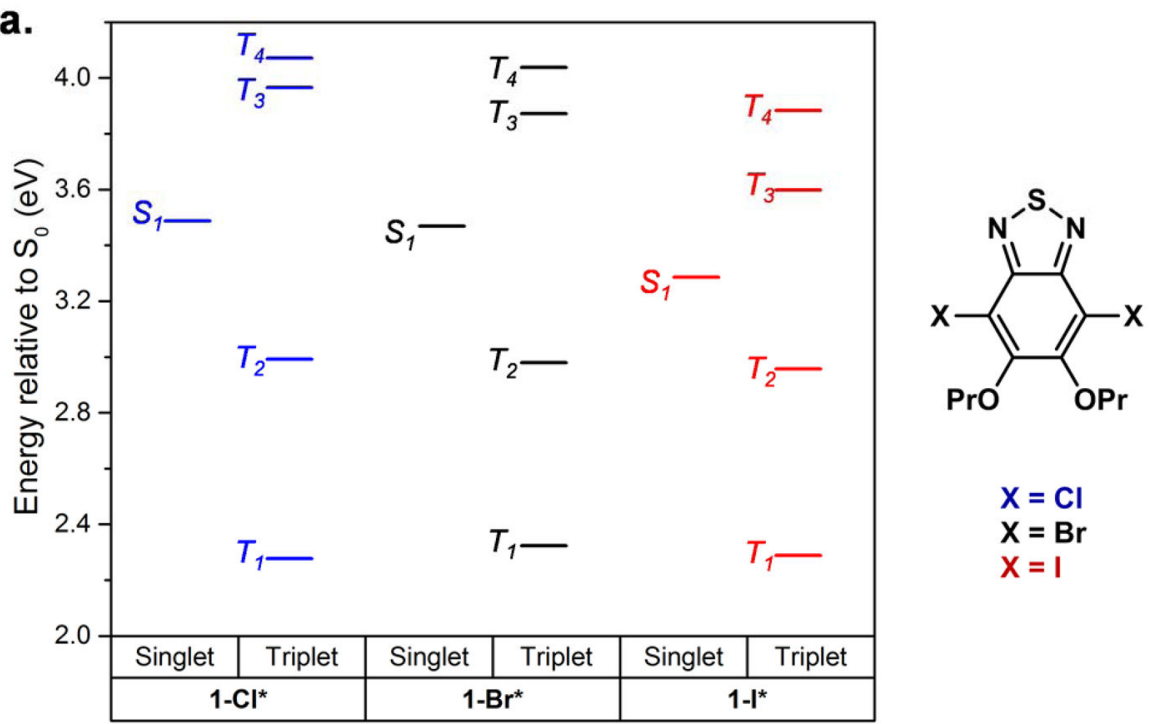

Figure 5a

b.
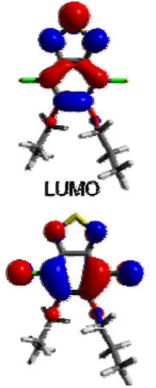

HOMO

$\mathrm{S}$,
$\left\langle\pi, x^{*}\right)$
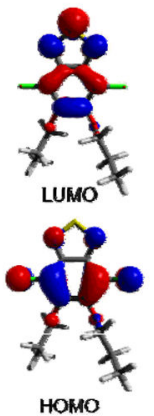

Hомо

$\mathrm{T}_{1}$
$\left(\pi, \pi^{*}\right)$
$1-\mathrm{C}^{*}$

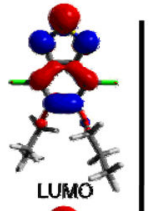

шим 7 шмо

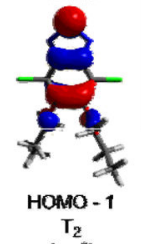

$\mathrm{T}_{2}$
$\left(\pi, z^{n}\right)$

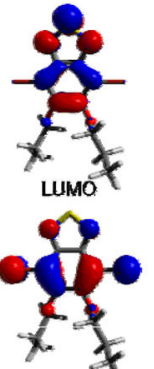

номо

$\mathrm{S}_{1}$
$\left(\pi, \pi^{*}\right)$
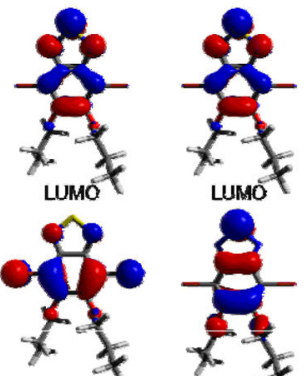

номо

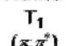

$\left(\pi, \pi^{*}\right)$

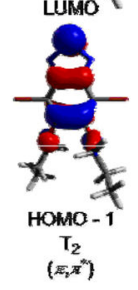

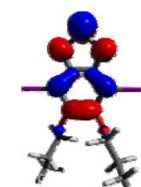
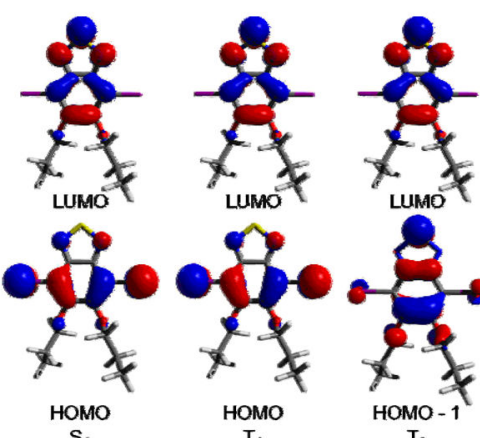

$\mathrm{S}_{1}$
$\left(\pi, \pi^{*}\right)$

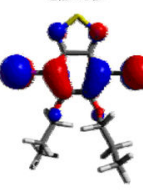

HОМо
$\mathrm{T}_{1}$
$\left(\pi, \pi^{*}\right)$

$1-1^{*}$

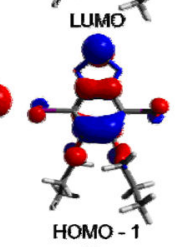

\section{Figure 5b}

Figure 5.

(a) Energy level diagrams for propoxy-functionalized derivatives 1-Cl*, 1-Br*, and 1-I* in the gas phase. (b) Kohn-Sham orbitals representing the electronic configuration descriptions of $S_{1}, T_{1}$, and $T_{2}$ for each calculated molecule. 
a.

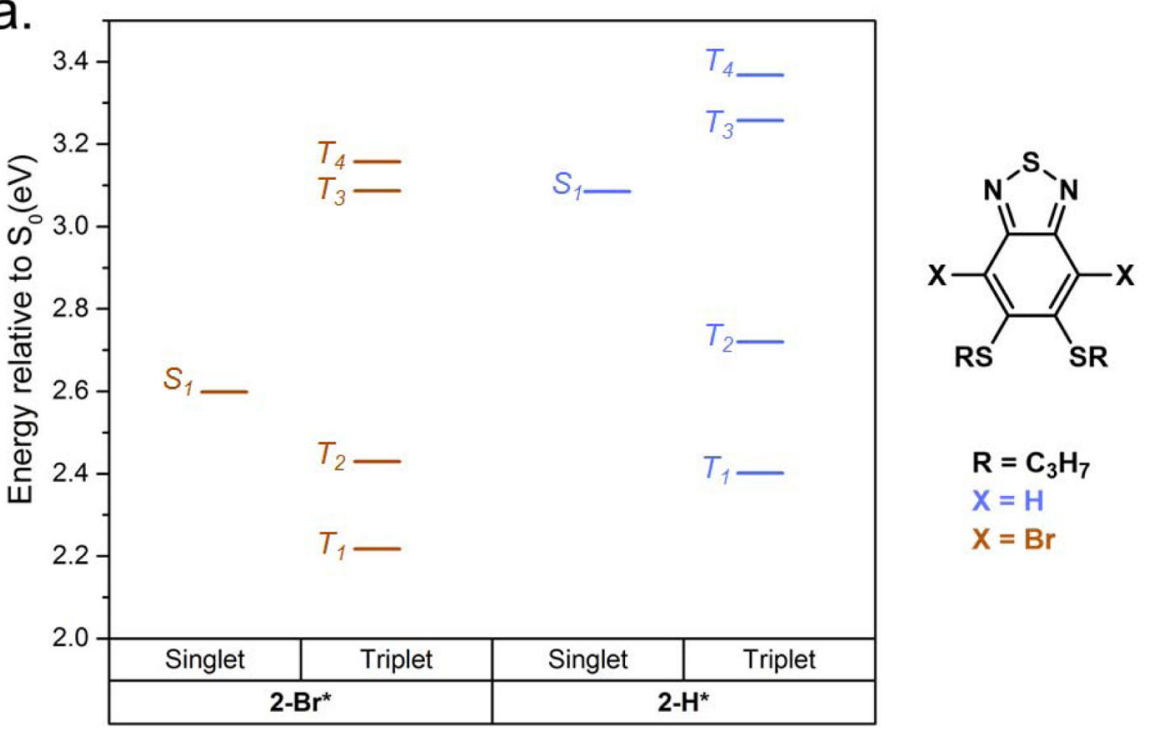

Figure 6a

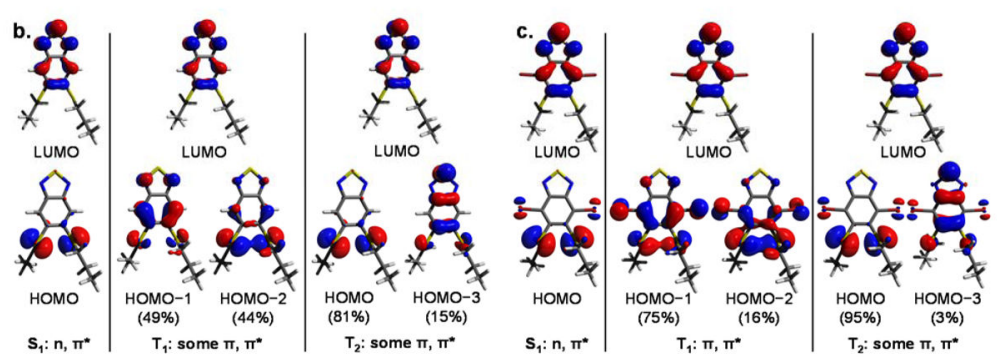

\section{Figure 6b}

Figure 6.

(a) Energy level diagrams for $\mathbf{2}-\mathbf{H}^{*}$ and $\mathbf{2}-\mathbf{B r}$ * in the gas phase. (b) Kohn-Sham orbitals representing the electronic configuration description of $\mathrm{S}_{1}, \mathrm{~T}_{1}$, and $\mathrm{T}_{2}$ manifolds of $\mathbf{2}-\mathbf{H}^{*}$ and (c) 2-Br* (c). Indicated percentages describe the overall character for each displayed transition. 

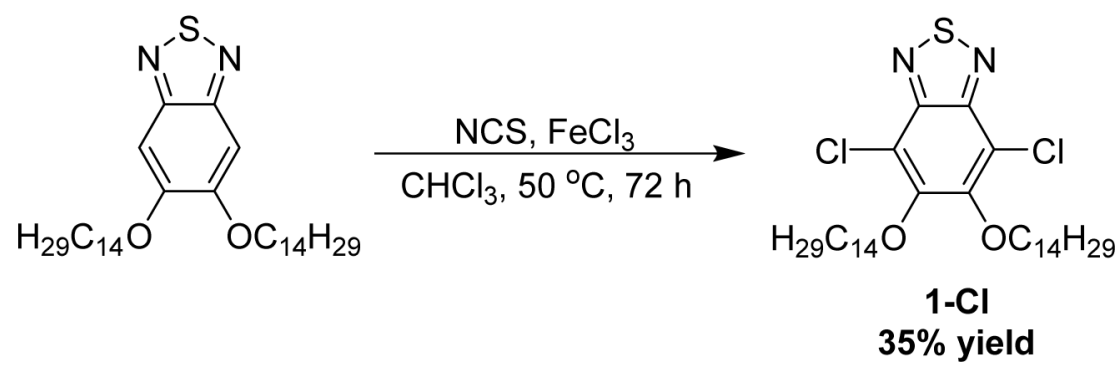

Scheme 1.

Synthesis of chlorinated benzo[2,1,3]thiadiazole 1-Cl. 
(a)

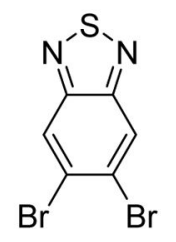

$$
\underset{\mathrm{PhMe},{ }^{\mathrm{i}} \mathrm{Pr}_{2} \mathrm{NEt}, 80^{\circ} \mathrm{C}, 19 \mathrm{~h}}{\stackrel{\mathrm{H}_{33} \mathrm{SH}, \mathrm{Pd}_{2} \mathrm{dba}_{3} \text {, XantPhos }}{\longrightarrow}}
$$

(b)

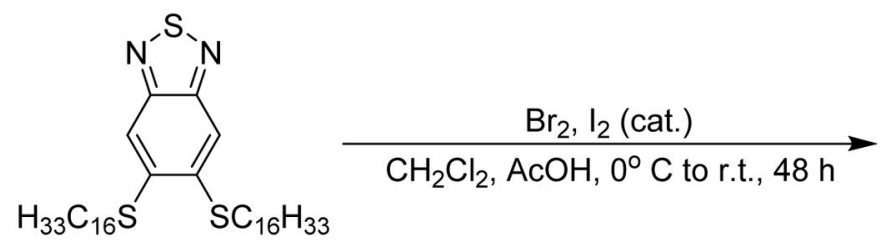

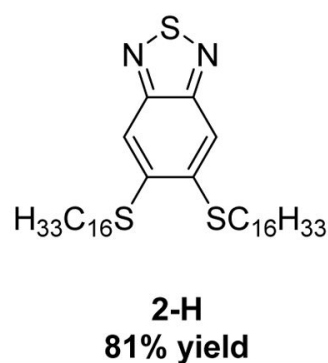

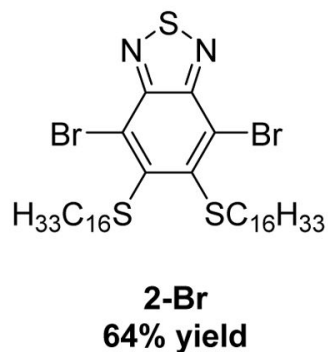

Scheme 2.

Syntheses of thioether-functionalized benzo[2,1,3]thiadiazoles 2-H (a) and 2- $\mathrm{Br}$ (b) 


\section{Table 1}

Summary of photophyscial properties of phosphorescent benzo[2,1,3]thiadiazoles in deoxygenated cyclohexane.

\begin{tabular}{lccc}
\hline Entry & $\lambda_{\text {abs,max }},{ }^{a} \lambda_{\text {em,max }}(\mathbf{n m})$ & $\tau_{\boldsymbol{P}}(\boldsymbol{\mu s})$ & $\boldsymbol{\Phi}_{\boldsymbol{P}}(\boldsymbol{\%})^{\boldsymbol{b}}$ \\
\hline $\mathbf{1 - B r}$ & 325,642 & 2.8 & 0.55 \\
1-I & 327,643 & 3.6 & 0.59 \\
$\mathbf{2 - H}$ & 382,624 & 5.4 & 0.70 \\
$\mathbf{2 - B r}$ & 347,667 & 3.4 & 0.50 \\
\hline
\end{tabular}

${ }^{a}$ Absorption maximum past $\lambda=300 \mathrm{~nm}$.

${ }^{b}$ Measured at $\lambda_{\mathrm{ex}}=370 \mathrm{~nm}$ using 9,10-diphenylanthracene in cyclohexane under air as a standard $(\Phi P L=77 \%) .{ }^{32}$ 